\title{
Indoor air quality, ventilation and respiratory health in elderly residents living in nursing homes in Europe
}

\author{
Malek Bentayeb ${ }^{1,2}$, Dan Norback ${ }^{3}$, Micha Bednarek $^{4}$, Alfred Bernard ${ }^{5}$, \\ Guihong $\mathrm{Cai}^{3}$, Sonia Cerrai ${ }^{6}$, Konstantinos Kostas Eleftheriou ${ }^{7}$, \\ Christina Gratziou" ${ }^{7}$, Gitte Juel Holst ${ }^{8}$, François Lavaud ${ }^{9}$, Jacek Nasilowski ${ }^{4}$, \\ Piersante Sestini ${ }^{10}$, Giuseppe Sarno ${ }^{6}$, Torben Sigsgaard ${ }^{8}$, Gunilla Wieslander ${ }^{3}$, \\ Jan Zielinski, ${ }^{4,}$, Giovanni Viegi ${ }^{6,11}$ and Isabella Annesi-Maesano ${ }^{1,2}$ on behalf of \\ the GERIE Study
}

\begin{abstract}
Affiliations: ${ }^{1}$ INSERM, U1136 IPLESP EPAR, Paris, France. ${ }^{2}$ Université Pierre et Marie Curie - Sorbonne Universités, UMR S 1136 IPLESP EPAR, Paris, France. ${ }^{3}$ Dept of Medical Science, Occupational and Environmental Medicine, Uppsala University, University Hospital, Uppsala, Sweden. ${ }^{4} 2$ nd Dept of Respiratory Medicine, National Research Institute of Tuberculosis and Lung Diseases, Warsaw, Poland. ${ }^{5}$ Dept of Public Health, Catholic University of Louvain, Brussels, Belgium. ${ }^{6}$ Pulmonary Environmental Epidemiology Unit, CNR Institute of Clinical Physiology, Pisa, Italy. ${ }^{7}$ Pulmonary and Critical Care Dept, Asthma Centre, Athens University, Athens, Greece. ${ }^{8}$ Section of Environment, Occupation and Health, Dept of Public Health, University of Aarhus, Aarhus, Denmark. 'Service de Pneumologie et Allergologie CHU Reims, Reims, France. ${ }^{10}$ Institute of Respiratory Diseases, Siena, Italy. ${ }^{11} \mathrm{CNR}$ Institute of Biomedicine and Molecular Immunology, Palermo, Italy.
\end{abstract}

Correspondence: Isabella Annesi-Maesano, EPAR, UMR S 1136, INSERM-UPMC-Paris 6, Medical School St Antoine, 27 rue Chaligny, 75571 Paris, France. E-mail: isabella.annesi-maesano@inserm.fr

ABSTRACT Few data exist on respiratory effects of indoor air quality and comfort parameters in the elderly. In the context of the GERIE study, we investigated for the first time the relationships of these factors to respiratory morbidity among elderly people permanently living in nursing homes in seven European countries.

600 elderly people from 50 nursing homes underwent a medical examination and completed a standardised questionnaire. Air quality and comfort parameters were objectively assessed in situ in the nursing home. Mean concentrations of air pollutants did not exceed the existing standards.

Forced expiratory volume in $1 \mathrm{~s} /$ forced vital capacity ratio was highly significantly related to elevated levels of particles with a 50\% cut-off aerodynamic diameter of $<0.1 \mu \mathrm{m}$ (PMo.1) (adjusted OR 8.16, 95\% CI 2.24-29.3) and nitrogen dioxide (aOR 3.74, 95\% CI 1.06-13.1). Excess risks for usual breathlessness and cough were found with elevated PM10 (aOR 1.53 (95\% CI 1.15-2.07) and aOR 1.73 (95\% CI 1.17-10.3), respectively) and nitrogen dioxide (aOR 1.58 (95\% CI 1.15-2.20) and aOR 1.56 (95\% CI 1.03-2.41), respectively). Excess risks for wheeze in the past year were found with PM0.1 (aOR 2.82, 95\% CI 1.157.02) and for chronic obstructive pulmonary disease and exhaled carbon monoxide with formaldehyde (aOR 3.49 (95\% CI 1.17-10.3) and aOR 1.25 (95\% CI 1.02-1.55), respectively). Breathlessness and cough were associated with higher carbon dioxide. Relative humidity was inversely related to wheeze in the past year and usual cough. Elderly subjects aged $\geqslant 80$ years were at higher risk. Pollutant effects were more pronounced in the case of poor ventilation.

Even at low levels, indoor air quality affected respiratory health in elderly people permanently living in nursing homes, with frailty increasing with age. The effects were modulated by ventilation.

$@$ ERSpublications

Poor air quality in European nursing homes impairs respiratory health in the elderly permanently living in them http://ow.ly/Es8VQ

A press release for this article is available from erj.ersjournals.com/site/misc/presspack.xhtml

Received: May 152013 | Accepted after revision: Nov 112014 | First published online: March 122015

Support statement: The GERIE study was funded by the European Commission's Directorate General for Health and Consumer Protection (DG-SANCO; contract no. 2006343) and the French Agency for Environment and Energy Management (ADEME; contract no. 0862 C 0076).

Conflict of interest: Disclosures can be found alongside the online version of this article at erj.ersjournals.com

Copyright CERS 2015 


\section{Introduction}

In industrialised countries, the main challenge for the future is the ageing population, particularly the increasing number of very old people (aged $>80$ years). By 2030, there will be 34.7 million citizens aged $>80$ years in the European Union [1], compared to 18.8 million at present. Ageing leads to the deterioration of immune defences and lung function, and predisposition to respiratory infections [2]. At present, keeping the elderly healthy by preventing chronic diseases is a major concern for many countries. This requires a better understanding of the health consequences of the exposure to environmental factors, including air pollution.

Adverse respiratory health effects due to air pollution are well established [3-5]. Various studies have demonstrated a relationship between outdoor air pollution and respiratory morbidity [6,7] and mortality $[8,9]$ in this age group at the general population level after stratification for age. A recent systematic review on adverse respiratory effects of outdoor air pollution in the elderly indicated that exposure to outdoor air pollution in the elderly leads to increased hospital admissions for asthma and chronic obstructive pulmonary disease (COPD) and higher COPD mortality than in the rest of the population. It also indicated that research on the health effects of air pollution in the elderly has been affected by methodological problems, in terms of exposure and health effect assessments and the lack of multicentre studies using the same standardised protocol and methodology in order to obtain comparable data [10]. Respiratory health effects of indoor air pollution have also been documented in the general population [11], but only rarely in the elderly [12-17]. However, in industrialised countries the elderly spend most of their time indoors [11] and $\sim 5 \%$ of those aged $>65$ years and $20 \%$ of those aged $>85$ years are nursing home residents (www.uscare.com). Indoor temperature, relative humidity and carbon dioxide $\left(\mathrm{CO}_{2}\right) \mathrm{can}$ also contribute to respiratory health issues $[18,19]$.

The specific objective of the GERIE study (Geriatric study on health effects of air quality in nursing homes in Europe) (www.geriestudy.eu) was to contribute to filling the gaps in knowledge that exist in the field health effects of indoor air quality in the elderly. This was achieved by exploring the relationships of common indoor air pollutants and comfort parameters to respiratory symptoms and diseases among the elderly permanently living in nursing homes, who are potentially at high risk of exposure to air indoor air pollution from usual nursing home activities, such as cleaning and disinfection.

\section{Methods}

The protocol of the GERIE study has been described in detail elsewhere [20].

\section{Study population}

Eight nursing homes were randomly selected in a geographical area representative of the selected city in each of the seven countries participating in the GERIE study (Belgium, Denmark, France, Greece, Italy, Poland and Sweden). In each nursing home, at least 20 randomly selected individuals aged $>65$ years who were living there permanently were invited to participate. Participants with neurological or psychiatric disorders were excluded. In case of refusal at recruitment or exclusion, other individuals were randomly chosen in the same nursing home in order to attain the fixed sample of individuals able to participate in the survey. All the subjects were invited to undergo a clinical visit including a physical examination, clinical tests and a face-to-face interview based on standardised instruments, after having signed a consent form. Measurements of indoor and outdoor air quality and comfort variables were simultaneously performed. The study protocol was approved by the ethical committee of each country as requested by the country law. Data were collected as follows: between February and March 2009 in Uppsala, Sweden; June 2009 in Warsaw, Poland; December 2009 in Athens, Greece; between May and July 2010 in Reims, France; February 2011 in Arezzo, Italy; September 2011 in Aarhus, Denmark; and October 2011 in Brussels, Belgium. The same trained team visited all the countries in order to determine reproducibility of the assessments.

\section{Environmental assessments}

Environmental measurements were performed outdoors and indoors in the nursing homes in Brussels, Aarhus, Athens, Reims, Arezzo, Warsaw and Uppsala. In every country, all the measurements were performed with the same methods and equipment.

Indoor air pollutants included particles with a 50\% cut-off aerodynamic diameter of $<10 \mu \mathrm{m}$ (PM10), PM0.1, formaldehyde, nitrogen dioxide $\left(\mathrm{NO}_{2}\right)$ and ozone and were objectively measured in the main common room (used for recreation, watching TV, meetings or dining) where the participants spent most of their time. Formaldehyde was measured using a diffusion sampler with a glass fiber filter impregnated with 2,4-dinitro-phenylhydrazine [21]. The filter was analysed by liquid chromatography. The uptake rate used for 1 week of sampling was $20.4 \mathrm{~mL} \mathrm{~min}^{-1}$. $\mathrm{NO}_{2}$ and ozone were measured using a "badge type" 
sampler based on the theory of diffusion sampling. Outdoor formaldehyde was assessed using the same methodology.

Particles were measured with P-Trak (model 8525, ultrafine particle counter; TSI Inc., Missoula, MT USA), which measured particles $0.02-1 \mu \mathrm{m}$ in size (number concentration), and Dust-Trak TM (model 8520; TSI Inc.), which measured particles $\sim 0.3-10 \mu \mathrm{m}$ in size. The instruments were calibrated by the TSI service laboratories. The measuring time was $5-7 \mathrm{~h}$ for P-Trak and $22-26 \mathrm{~h}$ for Dust-Trak. The instruments were placed on a desk or chair at the same heights as the breathing zone of the residents. Outdoor measurements were performed for $1 \mathrm{~h}$ at each nursing home (using Dust-Trak, P-Trak and Q-Trak (TSI Inc.)).

In each nursing home, indoor climate was measured in the same main common room as the air quality measurements. Room temperature, relative air humidity and $\mathrm{CO}_{2}$ were measured with a Q-Trak TM IAQ monitor and sampling for 1-min average intervals. Measurements were performed over $22-26 \mathrm{~h}$. Information about nursing home ventilation (absence or presence of poor versus adequate ventilation) was provided by the nursing home directors. The director reported it on the basis of American Society of Heating, Refrigerating and Air-Conditioning Engineers/European ventilation standards for healthcare residences according to which a ventilation rate $<15 \mathrm{~L} \cdot \mathrm{s}^{-1} \cdot 100 \mathrm{~m}^{-2}$ plus $3.5 \mathrm{~L} \cdot \mathrm{s}^{-1} \cdot$ person ${ }^{-1}$ for the common parts of the nursing home is considered as poor. All samplers were prepared and analysed at an accredited laboratory (IVL Swedish Environmental Research Institute, Gothenburg, Sweden).

\section{Health assessments}

Participants underwent a medical visit and replied to a standardised questionnaire on sociodemographic factors, and health and potential risk factors, derived from those used in the European Commission-funded Indicators for Monitoring COPD and Asthma in the EU study, including the European Community Respiratory Health Survey questions for respiratory health and related risk factors [22], and the French Three-City study $[6,23]$ study. Respiratory diseases assessed during the study included lifetime asthma ("has your doctor or other healthcare provider ever told you that you had asthma?"), lifetime COPD ("has your doctor or other healthcare provider ever told you that you have COPD?"), wheezing in the past year ("have you had wheezing and whistling in the chest during the past 12 months"), usual breathlessness ("are you troubled by shortness of breath when hurrying on the level or walking up a slight hill?"), usual cough ("do you usually cough when you don't have a cold ?”), and usual phlegm ("do you usually bring up phlegm from your chest, or do you usually have phlegm in your chest that is difficult to bring up when you don't have a cold ?"). Reported current cardiovascular diseases were also recorded. Based on spirometry during the clinical visit, airways obstruction was defined as a forced expiratory volume in $1 \mathrm{~s}\left(\mathrm{FEV}_{1}\right)$ /forced vital capacity $(\mathrm{FVC})$ ratio $<70 \%$. Lung function was assessed in all participants according to the American Thoracic Society/European Respiratory Society guidelines for spirometry using a SpiroUsb (Care Fusion, Wurzburg, Germany). FEV1 \% predicted, FVC \% pred and FEV1/FVC were collected in the following analyses. Height $(\mathrm{m})$ and weight $(\mathrm{kg})$ were assessed by a nurse and body mass index (BMI), defined as weight/height ${ }^{-2}\left(\mathrm{~kg} \mathrm{~m}^{-2}\right)$, was computed. As a marker of lower airways inflammation, exhaled $\mathrm{NO}(\mathrm{eNO})$ was assessed using a chemiluminescent $\mathrm{NO}$ analyser (NIOX NO analyser; Aerocrine, Solna, Sweden) according to American Thoracic Society/European Respiratory Society recommendations. Briefly, the individual was comfortably seated and breathed quietly for $\sim 5 \mathrm{~min}$ to acclimatise. Inspired gas should have contained low NO $(<5 \mathrm{ppb})$. The individual inhaled to near total lung capacity and immediately exhaled at a constant flow of $50 \mathrm{~mL} \cdot \mathrm{s}^{-1}$ until an NO plateau of at least $2 \mathrm{~s}$ was identified during an exhalation of at least $4 \mathrm{~s}$. The expiratory pressure should have been maintained between 5 and $20 \mathrm{cmH}_{2} \mathrm{O}$ to close the velum. Repeated exhalations (three within $10 \%$ agreement or two within 5\% agreement) were performed with a 30-s interval and mean NO was recorded. The EC-50 Smokerlyser (Bedfont Instruments, Maidstone, UK) was used to assess exhaled carbon monoxide (eCO) as an indicator of exposure to $\mathrm{CO}$ and, eventually, smoking habits. Each subject was asked to provide two breaths for testing, since it is known that the second reading will be significantly higher than the first. eNO was expressed in ppb and eCO in ppm.

\section{Statistical analysis}

During the period of assessment, the mean and median values of air pollutants (PM10, formaldehyde, $\mathrm{NO}_{2}$ and ozone $\left(\mu \mathrm{g} \mathrm{m}^{-3}\right)$ and $\left.\mathrm{PM} 0.1\left(\mathrm{ptcm}^{-3}\right)\right), \mathrm{CO}_{2}$ concentration $(\mathrm{ppm})$, temperature $\left({ }^{\circ} \mathrm{C}\right)$ and relative humidity (\%) were computed in each nursing home. The prevalence of respiratory health conditions was expressed as the percentage of positive responses to the corresponding questions. For the purpose of the present analyses, the concentrations of air pollutants and the comfort parameters of the main common room of the nursing home in which they lived were attributed to each individual. Confounders were described as mean (quantitative variables) or percentages (qualitative variables). These included sex, age, country, BMI, highest school level, smoking and season. 
To quantify the link of exposure to each air pollutant and indoor climate to health outcomes, and because of the nonlinearity of the relationships, exposure was classified as a categorical variable, namely "low" versus "high", with the latter being defined with respect to the median value of the distribution of each pollutant. Initially, the prevalence of health outcomes was calculated in each category of exposure, and unadjusted odds ratios with $95 \%$ confidence intervals were calculated and the associated probability estimated using a contingence table for the Chi-squared test.

Subsequently, the generalised estimating equation approach, with exchangeable covariance matrix to adjust for correlations within the elderly belonging to the same nursing home, was performed to estimate the odds ratio with 95\% confidence interval for the relationship of exposure to each indoor air pollutant (or indoor climate) and to each health outcome adjusted for potential confounders (adjusted odds ratio). The same model was performed taking into account the centre. Variables associated with respiratory health outcomes in bivariate analyses with a p-value $<0.20$ were considered as confounders.

Analyses stratified according to age group ( $<80$ years or $\geqslant 80$ years) was conducted in order to explore the hypothesis of increased frailty with ageing. In case of significant relationships between indoor air pollution, indoor comfort parameters and respiratory outcomes, stratification according to the presence or absence of ventilation in the nursing home was conducted.

Significant odds ratios were adjusted in a final model based on whether the subjects were suffering from a cardiovascular disease during the survey. Analyses were performed with SAS version 9.3 (PROC GENMOD; SAS Institute Inc., Cary, NC, USA) for the multivariate models.

\section{Results}

Characteristics of population

50 nursing homes agreed to participate in the GERIE study. In total, 600 (50\%) elderly people permanently living in these nursing homes were selected to participate in the GERIE study (table 1). On average, they were 82 years of age $(\sim 63 \%$ were $\geqslant 80$ years), were more often female $(\sim 72 \%)$ and had a poor education status (228 (38\%) had never attended school or had only attended primary school). In the data presented in the tables and figures, the numbers refer to the sample without missing data. The highest education level attained was in Poland, with $\sim 21 \%$ of the elderly having attended some or 4-year college. Of the participants, 210 (35\%) declared that they smoked. The mean BMI was $26.8 \mathrm{~kg} \mathrm{~m}^{-2}$. Breathlessness was the most frequently reported respiratory outcome $(\sim 33 \%$, with the highest prevalence observed in Belgium $(50 \%))$, followed by usual cough $(\sim 25 \%)$, usual phlegm $(\sim 20 \%)$ and wheezing in the past year (table 1$)$. Asthma and COPD were reported equally ( $\sim 6 \%)$. On the basis of spirometry, $\sim 6 \%$ of individuals presented with airway obstruction during the study period, only four were asthmatics. Lung function varied among the countries. FEV1 ranged from 75\% pred in Aarrhus to 95\% pred in Warsaw, and FVC ranged from $66 \%$ pred in Denmark to $105 \%$ pred in Poland. The highest eNO value was observed in Uppsala ( 26 ppb) and the lowest in Warsaw ( 17 ppb); eCO values ranged from $3 \mathrm{ppm}$ in Uppsala and Italy to $\sim 7 \mathrm{ppm}$ in Warsaw.

\section{Chemical indoor air pollution}

The distributions of indoor air pollutant concentrations objectively measured in the nursing homes participating in the GERIE study significantly varied among countries (fig. 1). The mean concentrations of air pollutants were as follows: PM10 $29.8 \mu \mathrm{g} \cdot \mathrm{m}^{-3}, \mathrm{PM} 0.112907 \mathrm{pt} \cdot \mathrm{cm}^{-3}$, formaldehyde $7.21 \mu \mathrm{g} \cdot \mathrm{m}^{-3}, \mathrm{NO}_{2}$ $20.1 \mu \mathrm{g} \cdot \mathrm{m}^{-3}$ and ozone $21.1 \mu \mathrm{g} \cdot \mathrm{m}^{-3}$. The highest values of $\mathrm{PM} 10, \mathrm{PM} 0.1$ and $\mathrm{NO}_{2}$ were observed in Athens $\left(56 \mu \mathrm{g} \cdot \mathrm{m}^{-3}, 23839 \mathrm{pt} \cdot \mathrm{cm}^{-3}\right.$ and $36.2 \mu \mathrm{g} \cdot \mathrm{m}^{-3}$, respectively). The highest values for formaldehyde and ozone were found in Aarhus $\left(13.7 \mu \mathrm{g} \cdot \mathrm{m}^{-3}\right)$ and Brussels $\left(42 \mu \mathrm{g} \cdot \mathrm{m}^{-3}\right)$. Mean levels of PM10, PM0.1 and $\mathrm{NO}_{2}$ were similar inside and outside the nursing home.

\section{Indoor comfort parameters and ventilation}

Table 2 shows the distribution of exposure and comfort among participants of the GERIE study according to country. On average, the indoor temperature was $23^{\circ} \mathrm{C}$ (lowest in Greece, $\sim 22^{\circ} \mathrm{C}$ ) (table 2), relative humidity was $37 \%$ (highest in Brussels, $~ 57 \%$ ) and $\mathrm{CO}_{2}$ was $<1000 \mathrm{ppm}$ in all nursing homes (highest in the Mediterranean countries and Belgium, lowest in Sweden). Only $105(\sim 18 \%)$ individuals had an adequate ventilation system in the nursing home where they lived (table 2).

\section{Associations of environmental exposures with respiratory health status}

Exposure to high levels of PM10 and $\mathrm{NO}_{2}$ was significantly associated with usual breathlessness and cough, whilst high levels of exposures to PM0.1 were significantly associated with wheeze in the past year and high concentrations of formaldehyde with reported COPD (table 3). Airway obstruction objectively assessed by FEV $1 / F V C<70 \%$ was positively related to $\mathrm{PM} 0.1$ and $\mathrm{NO}_{2}$ (table 3). Among the other respiratory 
TABLE 1 Participants' sociodemographic and health characteristics in the GERIE study according to country

\begin{tabular}{|c|c|c|c|c|c|c|c|c|c|}
\hline & All & Poland & Sweden & Greece & France & Italy & Denmark & Belgium & No response \\
\hline Subjects $\mathbf{n}$ & 600 & 170 & 55 & 84 & 134 & 63 & 60 & 34 & \\
\hline \multicolumn{10}{|l|}{ Sociodemographics } \\
\hline Females & $431(71.8)$ & $133(78.2)$ & $36(65.5)$ & $60(71.4)$ & $100(74.6)$ & $35(55.6)$ & $40(66.7)$ & $27(79.4)$ & $17(2.8)$ \\
\hline Age years & $82 \pm 9.5$ & $82 \pm 7.1$ & $86 \pm 10.1$ & $82 \pm 14.1$ & $81 \pm 8.7$ & $81 \pm 9.3$ & $83 \pm 8.3$ & $83 \pm 8.6$ & $26(4.3)$ \\
\hline \multicolumn{10}{|l|}{ Age group } \\
\hline$<80$ years & 197 (32.8) & 59 (34.7) & $10(18.1)$ & $27(32.1)$ & $53(39.6)$ & 22 (34.9) & $17(28.3)$ & $9(26.5)$ & \\
\hline$\geqslant 80$ years & 377 (62.8) & $103(60.6)$ & 45 (81.8) & $57(67.9)$ & 78 (58.2) & $29(46)$ & $40(66.7)$ & 25 (73.5) & \\
\hline BMI kg m${ }^{-2}$ & $26.8 \pm 6.4$ & $27.3 \pm 6.5$ & $25.4 \pm 6.6$ & $26.1 \pm 6.8$ & $27.4 \pm 5.6$ & $25.4 \pm 4.5$ & $27.9 \pm 8.2$ & $24.6 \pm 4.6$ & $124(20.6)$ \\
\hline Education & & & & & & & & & $96(16)$ \\
\hline None or primary school & $228(38)$ & $61(35.9)$ & $28(50.9)$ & $8(9.5)$ & $54(40.3)$ & 26 (41.3) & 45 (75) & $6(17.7)$ & \\
\hline Middle or high school & 198 (33) & $63(37.1)$ & $16(29.1)$ & 49 (58.3) & $51(38.1)$ & $1(1.6)$ & $1(1.7)$ & $17(50)$ & \\
\hline College for $\geqslant 4$ years & 78 (13) & $35(20.6)$ & $6(10.9)$ & $5(5.9)$ & $17(12.7)$ & $1(1.6)$ & $6(10)$ & $8(23.5)$ & \\
\hline \multicolumn{10}{|l|}{ Smoking status } \\
\hline Active smoker & $210(35)$ & 73 (42.9) & $18(32.7)$ & $23(27.4)$ & $35(26.1)$ & $13(20.6)$ & $32(53.3)$ & $16(47.1)$ & $78(13)$ \\
\hline Passive smoker & $83(13.8)$ & $2(1.2)$ & $12(21.8)$ & & 52 (38.8) & $7(11.1)$ & 9 (15) & $1(2.9)$ & $164(27.3)$ \\
\hline \multicolumn{10}{|l|}{ Respiratory health status } \\
\hline Asthma & $33(5.5)$ & $10(5.9)$ & $2(3.6)$ & $3(3.6)$ & $11(8.2)$ & $3(4.7)$ & $1(1.7)$ & $3(8.8)$ & 99 (16.5) \\
\hline COPD & $34(5.7)$ & $3(1.8)$ & $0(0)$ & $6(7.1)$ & $12(8.9)$ & $2(3.1)$ & 8 (13.3) & $3(8.8)$ & 92 (15.3) \\
\hline Wheeze in past year & 70 (11.7) & $12(7.1)$ & $11(20)$ & $4(4.8)$ & $23(17.1)$ & $7(11.1)$ & $10(16.6)$ & $3(8.8)$ & $95(15.8)$ \\
\hline Breathlessness in past year & $197(32.8)$ & 61 (35.9) & $21(38.2)$ & $15(17.9)$ & $59(44)$ & $4(6.4)$ & 20 (33.3) & $17(50)$ & $195(32.5)$ \\
\hline Cough & $151(25.1)$ & $35(20.6)$ & $10(18.1)$ & $22(26.1)$ & $47(35.1)$ & $9(14.3)$ & $26(43.3)$ & $2(5.9)$ & $75(12.5)$ \\
\hline Phlegm & $121(20.1)$ & $25(14.7)$ & $17(30.9)$ & $9(10.7)$ & $37(27.6)$ & $10(15.8)$ & $19(31.6)$ & $4(11.7)$ & 86 (14.3) \\
\hline \multicolumn{10}{|c|}{ Respiratory functions and parameters } \\
\hline FEV $1 \%$ pred & $88 \pm 0.9$ & $95 \pm 1.3$ & & $79 \pm 0.3$ & $89 \pm 0.3$ & $83 \pm 0.3$ & $75 \pm 0.3$ & & $216(36)$ \\
\hline FVC \% pred & $90 \pm 0.3$ & $105 \pm 0.3$ & & $91 \pm 0.3$ & $81 \pm 0.2$ & $92 \pm 0.4$ & $66 \pm 0.2$ & & $216(36)$ \\
\hline $\mathrm{FEV}_{1} / \mathrm{FVC}<70 \%$ & $37 \pm 6.2$ & $31 \pm 18.2$ & & $4 \pm 4.8$ & $0 \pm 0$ & $2 \pm 3.2$ & $0 \pm 0$ & & $217(36.2)$ \\
\hline eNO ppb & $20.6 \pm 15.2$ & $17.2 \pm 12$ & $25.8 \pm 14.3$ & $18.5 \pm 10.1$ & $25.2 \pm 20$ & $19.3 \pm 14.3$ & & & 256 (42.7) \\
\hline eCO ppm & $5.1 \pm 4.1$ & $7.4 \pm 3.6$ & $3 \pm 5.7$ & $4.4 \pm 4.4$ & $3.8 \pm 2.6$ & $3 \pm 1.6$ & & & $157(26.1)$ \\
\hline
\end{tabular}



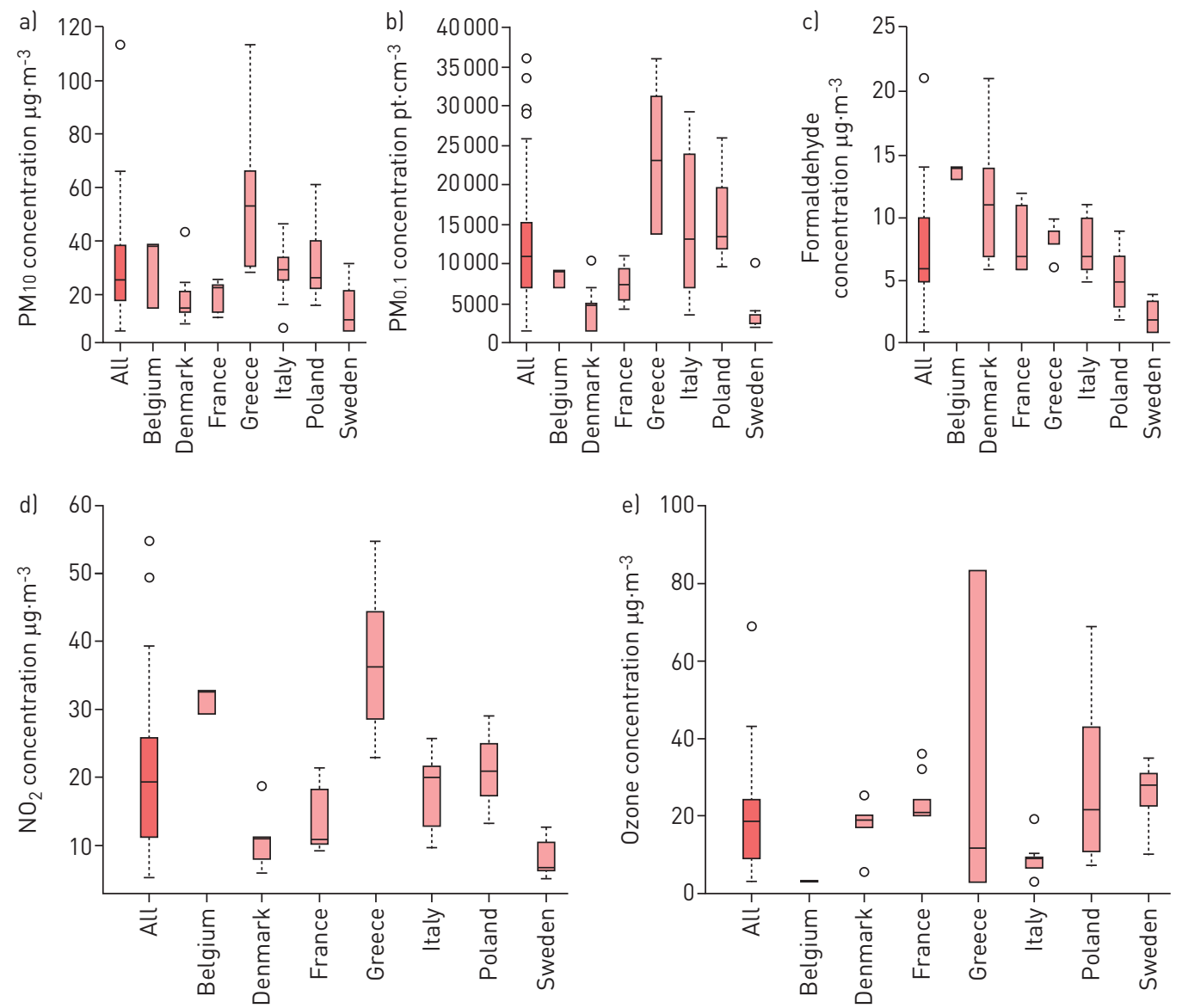

FIGURE 1 Box plots (interquartile range) and whiskers (range) of distribution of exposure to chemical air pollution among the subjects of the GERIE study according to country. The horizontal lines represent the median. PM10: particles with a $50 \%$ cut-off aerodynamic diameter of $<10 \mu \mathrm{m}$; PM0.1: particles with a $50 \%$ cut-off aerodynamic diameter of $<0.1 \mu \mathrm{m} ; \mathrm{NO}_{2}$ : nitrogen dioxide.

parameters, only FVC and eCO were significantly related to formaldehyde. As expected, there was an inverse relationship between eNO and $\mathrm{NO}_{2}$. Regarding the parameters of comfort, high levels of exposure to $\mathrm{CO}_{2}$ were significantly associated with usual breathlessness and cough, and a borderline significance was observed in cases of reported COPD and wheeze in the past year $(\mathrm{p}=0.054$ and $\mathrm{p}=0.057)$ (table 4$)$. Inverse relationships were found between elevated relative humidity and wheeze in the past year, usual cough and FEV $1 / F V C<70 \%$, and between exposure to high temperature and wheeze in the past year. Results did not change when taking into account the centre.

Stratification by age group showed a more pronounced effect of PM10 on usual breathlessness and cough among those aged $>80$ years compared to those aged $<80$ years (data not shown). More pronounced effects were also shown among this age group for the relationship between $\mathrm{NO}_{2}$ and usual breathlessness. Similarly, $\mathrm{CO}_{2}$ had a higher effect on wheeze in the past year and usual cough among participants aged $>80$ years (data not shown).

Stratification according to the presence of poor or adequate ventilation showed more pronounced effects of some air pollutants and comfort parameters on respiratory health in poorly ventilated nursing homes compared to adequately ventilated nursing homes (table 5). However, in adequately ventilated nursing homes the relationship of $\mathrm{CO}_{2}$ to breathlessness was also significant (adjusted OR 1.71, 95\% CI 1.08-2.70). All results persisted when adjusting for suffering from a cardiovascular disease during the study period.

\section{Discussion}

The effects of poor indoor air quality on respiratory symptoms and diseases among the elderly permanently living in nursing homes has not been characterised previously. In the present study, we showed a significant relationship between exposure to chemical indoor air pollutants and respiratory outcomes in the elderly, even at moderate concentrations of indoor air pollutants. Generally, the mean 
TABLE 2 Distribution of indoor comfort parameters and ventilation among the elderly in the GERIE study according to country

\begin{tabular}{|c|c|c|c|c|c|c|c|c|c|}
\hline & All & Poland & Sweden & Greece & France & Italy & Denmark & Belgium & No response \\
\hline $\begin{array}{l}\text { Subjects } \mathrm{n} \\
\text { Indoor comfort parameters }\end{array}$ & 600 & 170 & 55 & 84 & 134 & 63 & 60 & 34 & \\
\hline Temperature ${ }^{\circ} \mathrm{C}$ & $23 \pm 1.6$ & $22.9 \pm 0.6$ & $23.5 \pm 0.7$ & $22.4 \pm 2$ & $23.8 \pm 1.6$ & $23.1 \pm 2.1$ & $25.1 \pm 2.1$ & $23.7 \pm 0.9$ & $59(9.8)$ \\
\hline Relative humidity \% & $37 \pm 11.1$ & $31.8 \pm 2.4$ & $17.5 \pm 3.2$ & $46.4 \pm 3.7$ & $42.7 \pm 10.8$ & $32.9 \pm 4.5$ & $38.7 \pm 5.7$ & $56.7 \pm 6.4$ & $59(9.8)$ \\
\hline $\mathrm{CO}_{2} \mathrm{ppm}$ & $572 \pm 161.2$ & $462 \pm 54$ & $430.4 \pm 35$ & $715.5 \pm 104.1$ & $668.2 \pm 184.9$ & $627.3 \pm 143.3$ & $491.7 \pm 36.1$ & $742.4 \pm 169.3$ & $59(9.8)$ \\
\hline \multicolumn{10}{|l|}{ Ventilation } \\
\hline Poorly ventilated & $436(72.7)$ & $150(88.2)$ & $0(0)$ & $79(94.1)$ & 92 (68.7) & $63(100)$ & $18(30)$ & $34(100)$ & $59(9.8)$ \\
\hline Well ventilated & 105 (17.5) & $20(11.8)$ & $55(100)$ & $5(5.9)$ & $0(0)$ & $0(0)$ & $25(4)$ & $0(0)$ & \\
\hline
\end{tabular}

TABLE 3 Association between respiratory outcomes and indoor chemical air pollution in 600 subjects in the GERIE study

\begin{tabular}{|c|c|c|c|c|c|c|c|c|c|c|}
\hline & \multicolumn{2}{|l|}{ PM10 } & \multicolumn{2}{|l|}{ PMo.1 } & \multicolumn{2}{|c|}{ Formaldehyde } & \multicolumn{2}{|l|}{$\mathrm{NO}_{2}$} & \multicolumn{2}{|c|}{ Ozone } \\
\hline & aOR $(95 \% \mathrm{CI})$ & p-value & aOR $(95 \% \mathrm{CI})$ & p-value & aOR $(95 \% \mathrm{CI})$ & p-value & aOR $(95 \% \mathrm{CI})$ & p-value & aOR $(95 \% \mathrm{CI})$ & p-value \\
\hline Asthma & $1.00(0.55-1.84)$ & 0.983 & $1.20(0.65-2.24)$ & 0.541 & $0.44(0.12-1.56)$ & 0.209 & $1.12(0.63-2.01)$ & 0.669 & $1.13(0.63-2.09)$ & 0.652 \\
\hline Reported COPD & $0.94(0.19-4.43)$ & 0.933 & $1.40(0.22-9.11)$ & 0.715 & $3.49(1.17-10.3)$ & 0.023 & $1.09(0.15-7.61)$ & 0.926 & $0.94(0.30-2.94)$ & 0.918 \\
\hline Breathlessness & $1.53(1.15-2.07)$ & 0.003 & $1.00(0.54-1.84)$ & 0.988 & $0.52(0.19-1.39)$ & 0.194 & $1.58(1.15-2.20)$ & 0.005 & $1.15(0.86-1.53)$ & 0.315 \\
\hline Wheeze & $0.61(0.33-1.11)$ & 0.115 & $2.82(1.15-7.02)$ & 0.023 & $0.57(0.19-1.61)$ & 0.292 & $0.78(0.34-1.75)$ & 0.5592 & $0.61(0.34-1.09)$ & 0.100 \\
\hline Cough & $1.73(1.20-2.50)$ & 0.002 & $1.50(0.82-2.77)$ & 0.181 & $0.62(0.36-1.07)$ & 0.088 & $1.56(1.03-2.41)$ & 0.034 & $1.39(0.83-2.31)$ & 0.204 \\
\hline Phlegm & $0.85(0.50-1.41)$ & 0.532 & $1.04(0.55-1.95)$ & 0.898 & $0.99(0.46-2.07)$ & 0.963 & $0.69(0.45-1.02)$ & 0.064 & $1.22(0.71-2.13)$ & 0.458 \\
\hline FEV 1 & $1.16(0.87-1.56)$ & 0.303 & $1.00(0.88-1.13)$ & 0.958 & $1.12(0.97-1.28)$ & 0.106 & $1.04(0.85-1.28)$ & 0.656 & $1.18(0.93-1.50)$ & 0.166 \\
\hline FVC & $0.98(0.91-1.06)$ & 0.640 & $0.96(0.87-1.05)$ & 0.394 & $1.16(1.06-1.28)$ & 0.001 & $0.96(0.89-1.04)$ & 0.344 & $1.03(0.94-1.11)$ & 0.500 \\
\hline $\mathrm{FEV}_{1} / \mathrm{FVC}<70 \%$ & $2.53(0.70-9.11)$ & 0.156 & $8.16(2.24-29.3)$ & 0.001 & $0.46(0.12-1.66)$ & 0.237 & $3.74(1.06-13.1)$ & 0.038 & $0.69(0.23-2.03)$ & 0.508 \\
\hline eNO & $0.94(0.78-1.14)$ & 0.558 & $1.04(0.75-1.46)$ & 0.791 & $1.04(0.87-1.27)$ & 0.624 & $0.80(0.72-0.90)$ & 0.0002 & $0.96(0.78-1.18)$ & 0.686 \\
\hline eco & $0.97(0.76-1.23)$ & 0.789 & $0.77(0.58-1.03)$ & 0.079 & $1.25(1.02-1.55)$ & 0.031 & $1.03(0.88-1.20)$ & 0.722 & $0.93(0.73-1.18)$ & 0.549 \\
\hline
\end{tabular}

The p-values were obtained with the generalised estimating equation approach adjusted for sex, age, country, body mass index, highest school level, smoking, season and ventilation. Exposure was classified as a categorical variable, namely "low" versus "high", with respect to the median value of the distribution of the evaluated concentrations in the nursing home. Bold indicates statistical significance. PM10: particles with a $50 \%$ cut-off aerodynamic diameter of $<10 \mu \mathrm{m}$; $\mathrm{PM} 0.1$ : particles with a $50 \%$ cut-off aerodynamic diameter of $<0.1 \mu \mathrm{m} ; \mathrm{NO}_{2}$ : nitrogen dioxide; aOR: adjusted odds ratio; COPD: chronic obstructive pulmonary disease; FEV1: forced expiratory volume in $1 \mathrm{~s}$; FVC: forced vital capacity; eNO: exhaled nitric oxide; eCO: exhaled carbon monoxide. 
TABLE 4 Association between respiratory outcomes and indoor comfort parameters in 600 subjects in the GERIE study

\begin{tabular}{|c|c|c|c|c|c|c|}
\hline & \multicolumn{2}{|c|}{ Temperature } & \multicolumn{2}{|c|}{ Relative humidity } & \multicolumn{2}{|l|}{$\mathrm{CO}_{2}$} \\
\hline & aOR $(95 \%$ CI) & p-value & aOR $(95 \%$ CI) & p-value & aOR $(95 \% \mathrm{CI})$ & p-value \\
\hline Asthma & $1.27(0.74-2.20)$ & 0.376 & $0.80(0.44-1.40)$ & 0.436 & $1.09(0.67-1.78)$ & 0.718 \\
\hline Reported COPD & $0.61(0.17-2.11)$ & 0.443 & $2.71(0.58-12.6)$ & 0.204 & $2.94(0.98-8.84)$ & 0.054 \\
\hline Breathlessness & $0.93(0.65-1.30)$ & 0.662 & $1.06(0.69-1.63)$ & 0.754 & $1.68(1.32-2.15)$ & $<0.0001$ \\
\hline Wheeze & $0.55(0.31-0.99)$ & 0.043 & $0.18(0.09-0.36)$ & $<0.0001$ & $1.93(0.98-3.85)$ & 0.057 \\
\hline Cough & $0.95(0.61-1.46)$ & 0.805 & $0.70(0.50-0.98)$ & 0.037 & $2.01(1.55-2.63)$ & $<0.0001$ \\
\hline Phlegm & $0.97(0.62-1.47)$ & 0.873 & $1.20(0.77-1.91)$ & 0.395 & $0.87(0.49-1.56)$ & 0.660 \\
\hline FEV $_{1}$ & $1.19(0.87-1.62)$ & 0.263 & $1.03(0.84-1.25)$ & 0.758 & $1.23(0.84-1.81)$ & 0.290 \\
\hline FVC & $0.96(0.89-1.04)$ & 0.298 & $1.13(0.99-1.28)$ & 0.061 & $0.98(0.91-1.06)$ & 0.633 \\
\hline $\mathrm{FEV}_{1} / \mathrm{FVC}<70 \%$ & $0.45(0.13-1.56)$ & 0.211 & $0.15(0.05-0.42)$ & 0.0003 & $0.60(0.20-1.75)$ & 0.349 \\
\hline eNO & $0.97(0.80-1.16)$ & 0.720 & $0.90(0.65-1.25)$ & 0.534 & $0.95(0.74-1.22)$ & 0.714 \\
\hline eco & $1.12(0.89-1.41)$ & 0.340 & $1.25(0.95-1.64)$ & 0.115 & $0.99(0.76-1.28)$ & 0.937 \\
\hline
\end{tabular}

The $p$-values were obtained with the generalised estimating equation approach adjusted for sex, age, country, body mass index, highest school level, smoking, season and ventilation. Exposure was classified as a categorical variable, namely "low" versus "high", with respect to the median value of the distribution of the evaluated concentrations in the nursing home. Bold indicates statistical significance. aOR: adjusted odds ratio; $\mathrm{CO}_{2}$ : carbon dioxide; $\mathrm{COPD}$ : chronic obstructive pulmonary disease; FEV1: forced expiratory volume in $1 \mathrm{~s}$; FVC: forced vital capacity; eNO: exhaled nitric oxide; eCO: exhaled carbon monoxide.

concentrations of air pollutants did not exceed the existing international [24, 25] and national [26] standards (outdoor standards when indoor standards did not exist). The indoor mean level of PM10 was $>50 \mu \mathrm{g} \cdot \mathrm{m}^{-3}$ in only six (12\%) nursing homes and $\mathrm{NO}_{2}$ levels exceeded $40 \mu \mathrm{g} \cdot \mathrm{m}^{-3}$ in two (4\%) nursing homes, while the indoor level of ozone was very low, as expected. The formaldehyde levels were low and the maximum indoor level (weekly average) was $21 \mu \mathrm{g} \cdot \mathrm{m}^{-3}$. However, exposure to formaldehyde levels higher than the median value of the distribution was significantly related to a higher prevalence of COPD and COPD-like symptoms. Usual breathlessness and usual cough were significantly associated with high exposure to PM10 and $\mathrm{NO}_{2}$. Wheeze in the past year was associated with PM0.1. In addition, COPD defined on the basis of the FEV1/FVC ratio was highly related to both ultrafine PM0.1 and $\mathrm{NO}_{2}$.

Because of the absence of data, we cannot compare these results with previous epidemiological studies. However, our findings are compatible with a previous study conducted in elderly, which found a significant relationship between exposure to outdoor PM10 and bronchitis-like symptoms despite low concentrations [6]. In that study, as in this study, cardiac problems also related to breathlessness and dyspnoea had been taken into account. In terms of indoor air pollution, Osman et al. [27] showed a significant relationship between $\mathrm{COPD}$ and indoor $\mathrm{NO}_{2}$. To our knowledge, only two studies have reported respiratory health effects of volatile organic compounds (VOCs) in the elderly. In the first study, the urinary levels of hippuric acid and methylhippuric acid, which are metabolites of toluene and xylene, respectively, were significantly associated with reduction of FEV1, FEV1/FVC and forced expiratory flow at $25-75 \%$ of FVC [28]. The authors also found significant associations between VOC metabolites and markers of oxidative stress, which were associated with pulmonary function parameters. These results are in line with our findings relating formaldehyde to COPD. In our study, we also found a significant relationship of $\mathrm{PM} 0.1$ and $\mathrm{NO}_{2}$ to $\mathrm{FEV} 1 / \mathrm{FVC}<70 \%$, a criterion for diagnosing airway obstruction [29]. In the second study [30], which objectively assessed 20 VOCs in a population-based sample, the associations between breathlessness and living in dwellings with elevated concentrations of toluene and o-xylene, respectively, were statistically significant in the elderly (aOR 3.36 (95\% CI 1.13-9.98) and 2.85 (1.06-7.68), respectively) but not in the rest of the population (aOR $0.91(0.59-1.39)$ and $0.79(0.47-1.34)$, respectively); despite the fact that similar levels of indoor air pollutants were found in the elderly and others. PM2.5 has been related to a decline in lung function among the elderly [28] but no previous information about exposure to PM0.1 exists. However, indoor air quality in the nursing home is characterised by pollution mixture; therefore, it is difficult to conclude which indoor air contaminant had a specific and independent adverse effect on respiratory symptoms or disease in our study. In addition, it must be taken into account that multi-exposure requires adapted statistical methods [31], which has never previously been performed in the elderly.

Our study also provides original data on the effects of comfort parameters and ventilation in the elderly. In our study, $\mathrm{CO}_{2}$ was associated with usual breathlessness and cough and, to a lesser extent, with 
TABLE 5 Association between respiratory outcomes and indoor air pollutants and comfort parameters according to ventilation in the GERIE Study

\section{No or poor ventilation Adequate ventilation aOR $(95 \% \mathrm{Cl}) \quad$ aOR $(95 \% \mathrm{CI})$}

\begin{tabular}{|c|c|c|}
\hline \multicolumn{3}{|l|}{ Air pollutants } \\
\hline Wheezing in the past year and PM0.1 & $3.02(1.22-7.47)$ & NS \\
\hline Usual breathlessness and PM10 & $1.67(1.25-2.23)$ & NS \\
\hline Usual cough and $\mathrm{PM} 10$ & $1.83(1.32-2.54)$ & NS \\
\hline $\mathrm{FEV}_{1}$ and $\mathrm{PM}_{10}$ & NS & $0.33(0.20-0.53)$ \\
\hline FEV 1 and $\mathrm{PM}_{0.1}$ & NS & $0.23(0.14-0.41)$ \\
\hline FEV 1 and $\mathrm{NO}_{2}$ & NS & $0.28(0.17-0.46)$ \\
\hline FEV1 and formaldehyde & $2.65(1.29-5.45)$ & NS \\
\hline FVC and PM0.1 & $2.75(1.04-7.3)$ & NS \\
\hline $\mathrm{FVC}$ and $\mathrm{NO}_{2}$ & $2.62(1.08-6.38)$ & NS \\
\hline $\mathrm{eCO}$ and $\mathrm{PM} 10$ & $3.95(1.40-11.1)$ & NS \\
\hline $\mathrm{eCO}$ and $\mathrm{PM} 0.1$ & $12.5(2.22-70.6)$ & $6.24(1.87-20.8)$ \\
\hline $\mathrm{eCO}$ and $\mathrm{NO}_{2}$ & $5.03(1.56-16.1)$ & $3.93(1.24-12.4)$ \\
\hline \multicolumn{3}{|l|}{ Comfort parameters } \\
\hline Wheezing in the past year and temperature & $0.41(0.23-0.71)$ & NS \\
\hline Usual breathlessness and $\mathrm{CO}_{2}$ & $1.69(1.31-2.17)$ & $1.71(1.08-2.70)$ \\
\hline Usual cough and $\mathrm{CO}_{2}$ & $2.07(1.61-2.67)$ & NS \\
\hline $\mathrm{FEV} 1$ and $\mathrm{CO}_{2}$ & NS & $0.36(0.20-0.64)$ \\
\hline FEV 1 and relative humidity & $2.23(1.26-3.93)$ & NS \\
\hline FVC and temperature & $0.37(0.16-0.87)$ & NS \\
\hline eNO and $\mathrm{CO}_{2}$ & NS & $2.44(1.07-5.59)$ \\
\hline \multicolumn{3}{|c|}{$\begin{array}{l}\text { The p-values were obtained with the generalised estimating equation approach adjusted for sex, age, } \\
\text { country, body mass index, highest school level, smoking and season. Exposure was classified as a } \\
\text { categorical variable, namely "low" versus "high", with respect to the median value of the distribution of the } \\
\text { evaluated concentrations in the nursing home. Forced expiratory volume in } 1 \mathrm{~s}(\mathrm{FEV} \text { ) and forced vital } \\
\text { capacity (FVC) were classified as a categorical variable, namely "low" versus "high", with respect to the } \\
\text { 20th percentile value of the distribution. Exhaled nitric oxide (eNO) and exhaled carbon monoxide (eCO) } \\
\text { were classified as a categorical variable, namely "low" versus "high", with respect to the } 90 \text { th percentile } \\
\text { value of the distribution. aOR: adjusted odds ratio; PMo.1: particles with a } 50 \% \text { cut-off aerodynamic } \\
\text { diameter of }<0.1 \mu \mathrm{m} \text {; PM10: particles with a } 50 \% \text { cut-off aerodynamic diameter of }<10 \mu \mathrm{m} \text {; } \mathrm{NO}_{2} \text { : nitrogen } \\
\text { dioxide; } \mathrm{CO}_{2} \text { : carbon dioxide; NS: nonsignificant. }\end{array}$} \\
\hline
\end{tabular}

diagnosed COPD and wheeze in the past year, which was consistent with previous results in younger populations [19]. $\mathrm{CO}_{2}$ is also an indicator of poor ventilation [32]. In our study, where only $19 \%$ of the population had adequate ventilation, more respiratory outcomes were observed in relation to poor ventilation and a more pronounced effect of indoor air pollution and comfort parameters on respiratory outcomes were observed in the elderly permanently living in poorly ventilated nursing homes. These results are in agreement with previous findings [32] and show the importance of ventilation in the prevention of adverse effects of air pollution. In the study mentioned previously, in which the elderly were compared to the rest of the population, a more pronounced effect of $n$-decane on breathlessness in the past year was observed in the case of poor ventilation in the dwellings [30]. Temperature was negatively associated with wheeze in the past year in our study, implying that high temperatures might have a protective effect on wheeze among the elderly. A specific effect of low temperature is consistent with the fact that cold can be responsible for bronchial hyperresponsiveness [33]. However, according to the literature, at the population level both low and high temperatures may increase the risk of hospital admissions in the elderly [34]. Countries with lower socio-environmental conditions where extreme temperature conditions can be observed showed greater adverse health impacts [34]. Relative humidity was inversely associated with wheeze in the past year and usual cough in our study, which is not consistent with previous literature showing that humidity is a well-known risk factor for asthma, wheezing and asthma-like symptoms in the long term $[35,36]$; however, in an animal model humidity did not influence the position of the dose-response curve to methacholine in the short term [37].

In our study, stratification by age group showed that the older nursing home residents had a higher risk of reporting breathlessness in the case of exposure to $\mathrm{NO}_{2}$, and wheeze and cough in the case of high levels of $\mathrm{CO}_{2}$. This supports the hypothesis of a link between ageing and frailty. The susceptibility of older adults to the health effects of air pollution is well-recognised. Advanced age may act as a partial surrogate for 
conditions associated with ageing. Recently, EcKel et al. [38] investigated whether "gerontology" frailty (based on a clinical health status metric) modified the association between the ambient level of ozone and PM10 and lung function in 3382 older adults using 7 years of follow-up data (1990-1997) from the Cardiovascular Health Study and its Environmental Factors Ancillary Study. Frailty history was found to modify long-term associations of pollutants with FVC. The elderly could also be more exposed to indoor air pollutants because they spent most time indoors [12], which could put them at higher risk of adverse health effects of air pollution, compared to the rest of the population.

The strengths of our study include the fact that the GERIE study is the first multicentre, epidemiological study examining the effects of indoor air quality and indoor climate on respiratory morbidity in hundreds of elderly people in seven European countries using a standardised protocol. In addition, it provides indoor assessments in situ of indoor air pollution and comfort parameters in 50 European nursing homes using the same equipment and the same technicians [30]. Another strength is the fact that the statistical analyses were robust and adjusted for several confounding factors, taking into account country and nursing homes. Nonetheless, we also recognise some limitations of the study. Measurements of air quality were limited to a short period (1 week), which challenges their representativeness. As no reversibility test was conducted, we could not differentiate asthma from COPD in the elderly. However, it is well known that the diagnostic accuracy of bronchodilation for differentiating asthma from COPD is quite poor [39] overall in elderly [40]. This was also useless in our population where only four individuals presented with asthma and airflow obstruction simultaneously. In addition, the main aim of the GERIE study was to establish whether poor air quality and comfort variables endangered respiratory health in general. Finally, participants with dementia were excluded and replaced by residents who were able to answer to questions, thus, the population recruited in our study is not fully representative of elderly people commonly found in nursing homes. This could have led to a selection bias in favour of a healthier population.

In conclusion, the European GERIE study shows an independent effect of several indoor air pollutants and comfort parameters on respiratory morbidity among the elderly permanently living in nursing homes. These adverse effects were greater in the case of poor ventilation and in those aged $>80$ years. Since the effects of the studied air pollutants on respiratory morbidity may be confounded by other indoor air contaminants, further investigations are needed to enhance understanding of the underlying mechanism of frailty among the elderly.

\section{Acknowledgements}

We are indebted to the participants of the GERIE study, as well as to the health professionals in the nursing homes and the authorities.

\section{References}

1 Alliance for Health and the Future. Health in Europe: A Strategic Approach. Response to the European Commission's Discussion Document for a Health Strategy. http://ec.europa.eu/health/archive/ph_overview/ strategy/docs/r-040.pdf Date last updated: February 2007. Date last accessed: December 15, 2014.

2 Viegi G, Maio S, Simoni M, et al. The epidemiological link between ageing and respiratory diseases. In: Bellia V, Incalzi R. Respiratory Diseases in Elderly. ERS Monogr 2009; 43: 1-17.

3 Migliaretti G, Dalmasso P, Gregori D. Air pollution effects on the respiratory health of the resident adult population in Turin, Italy. Int J Environ Health Res 2007; 17: 369-379.

4 Atkinson RW, Anderson HR, Sunyer J, et al. Acute effects of particulate air pollution on respiratory admissions: results from APHEA 2 project. Air pollution and health: a European approach. Am J Respir Crit Care Med 2001; 164: $1860-1866$.

5 Roemer W, Hoek G, Brunekreef B, et al. Daily variations in air pollution and respiratory health in a multicentre study: the PEACE project. Pollution Effects on Asthmatic Children in Europe. Eur Respir J 1998; 12: 1354-1361.

6 Bentayeb M, Helmer C, Raherison C, et al. Bronchitis-like symptoms and proximity air pollution in French elderly. Respir Med 2010; 104: 880-888.

7 Connolly MJ, Lowe D, Anstey K, et al. Admissions to hospital with exacerbations of chronic obstructive pulmonary disease: effect of age related factors and service organisation. Thorax 2006; 61: 843-848.

8 Aga E, Samoli E, Touloumi G, et al. Short-term effects of ambient particles on mortality in the elderly: results from 28 cities in the APHEA2 project. Eur Respir J 2003; 21: Suppl. 40, 28s-33s.

9 Filleul L, Le Tertre A, Baldi I, et al. Difference in the relation between daily mortality and air pollution among elderly and all-ages populations in southwestern France. Environ Res 2004; 94: 249-253.

10 Bentayeb M, Simoni M, Baiz N, et al. Adverse respiratory effects of outdoor air pollution in the elderly. Int $J$ Tuberc Lung Dis 2012; 16: 1149-1161.

11 Hulin M, Simoni M, Viegi G, et al. Respiratory health and indoor air pollutants based on quantitative exposure assessments. Eur Respir J 2012; 40: 1033-1045.

12 Simoni M, Jaakkola MS, Carrozzi L, et al. Indoor air pollution and respiratory health in the elderly. Eur Respir J 2003; 21: Suppl. 40, 15s-20s.

13 Bentayeb M, Simoni M, Norback D, et al. Indoor air pollution and respiratory health in the elderly. J Environ Sci Health A Tox Hazard Subst Environ Eng 2013; 48: 1783-1789.

14 Perez-Padilla R, Schilmann A, Riojas-Rodriguez H. Respiratory health effects of indoor air pollution. Int J Tuberc Lung Dis 2010; 14: 1079-1086. 
15 Bernstein JA, Alexis N, Bacchus H, et al. The health effects of non-industrial indoor air pollution. J Allergy Clin Immunol 2008; 121: 585-591.

16 Abt E, Suh HH, Allen G, et al. Characterization of indoor particle sources: a study conducted in the metropolitan Boston area. Environ Health Perspect 2000; 108: 35-44.

17 Terzano C, Di Stefano F, Conti V, et al. Air pollution ultrafine particles: toxicity beyond the lung. Eur Rev Med Pharmacol Sci 2010; 14: 809-821.

18 Fraga S, Ramos E, Martins A, et al. Indoor air quality and respiratory symptoms in Porto schools. Rev Port Pneumol 2008; 14: 487-507.

19 Mi YH, Norback D, Tao J, et al. Current asthma and respiratory symptoms among pupils in Shanghai, China: influence of building ventilation, nitrogen dioxide, ozone, and formaldehyde in classrooms. Indoor Air 2006; 16: 454-464.

20 Annesi-Maesano I, Norback D, Zielinski J, et al. Geriatric study in Europe on health effects of air quality in nursing homes (GERIE study) profile: objectives, study protocol and descriptive data. Multidiscip Respir Med 2013; 8: 71.

21 Levin JO, Lindahl R, Andersson K. High performance liquid chromatographic determination of formaldehyde in indoor air in the ppb to ppm range using diffusive sampling and hydrazone formation. Environ Technol Lett 1988; 9: 1423-1430.

22 Castejon-Cervero MA, Jimenez-Parras R, Fernandez-Arias I, et al. Evaluation of compliance with the EGS guidelines in Spain, using Achievable Benchmarks of Care $\left(\mathrm{ABC}^{\otimes}\right)$ methodology: the IMCA Study. Eur J Ophthalmol 2011; 21: 149-155.

23 Zureik M, Gariepy J, Courbon D, et al. Alcohol consumption and carotid artery structure in older French adults: the Three-City Study. Stroke 2004; 35: 2770-2775.

24 World Health Organization. WHO air quality guidelines for particulate matter, ozone, nitrogen dioxide and sulfur dioxide. Global update 2005. Geneva, WHO, 2005.

25 World Health Organization. WHO guidelines for indoor air quality: selected pollutants. Geneva, WHO, 2010.

26 ANSES. Qualité de l'air intérieur. www.anses.fr/fr/content/qualit\%C3\%A9-de-1\%E2\%80\%99air-int\%C3\%A9rieur Date last updated: April 11, 2013. Date last accessed: December 15, 2014.

27 Osman LM, Douglas JG, Garden C, et al. Indoor air quality in homes of patients with chronic obstructive pulmonary disease. Am J Respir Crit Care Med 2007; 176: 465-472.

28 Lee JT, Son JY, Cho YS. The adverse effects of fine particle air pollution on respiratory function in the elderly. Sci Total Environ 2007; 385: 28-36.

29 Pauwels RA, Buist AS, Calverley PM, et al. Global strategy for the diagnosis, management, and prevention of chronic obstructive pulmonary disease. NHLBI/WHO Global Initiative for Chronic Obstructive Lung Disease (GOLD) Workshop summary. Am J Respir Crit Care Med 2001; 163: 1256-1276.

30 Bentayeb M, Billionnet C, Baiz N, et al. Higher prevalence of breathlessness in elderly exposed to indoor aldehydes and VOCs in a representative sample of French dwellings. Respir Med 2013; 107: 1598-1607.

31 Billionnet C, Sherrill D, Annesi-Maesano I. Estimating the health effects of exposure to multi-pollutant mixture. Ann Epidemiol 2012; 22: 126-141.

32 Norbäck D, Nordström K, Zhao Z. Carbon dioxide $\left(\mathrm{CO}_{2}\right)$ demand-controlled ventilation in university computer classrooms and possible effects on headache, fatigue and perceived indoor environment: an intervention study. Int Arch Occup Environ Health 2013; 86: 199-209.

33 Rundell KW, Anderson SD, Spiering BA, et al. Field exercise vs laboratory eucapnic voluntary hyperventilation to identify airway hyperresponsiveness in elite cold weather athletes. Chest 2004; 125: 909-915.

34 Silva EN, Ribeiro H. Impact of urban atmospheric environment on hospital admissions in the elderly. Rev Saude Publica 2012; 46: 694-701.

35 Kennedy K, Grimes C. Indoor water and dampness and the health effects on children: a review. Curr Allergy Asthma Rep 2013; 13: 672-680.

36 Koh YI, Choi IS. Seasonal difference in the occurrence of exercise-induced bronchospasm in asthmatics: dependence on humidity. Respiration 2002; 69: 38-45.

37 Arantes-Costa FM, Zoriki S, Santos MH, et al. Effects of ventilation, humidity and temperature on airway responsiveness to methacholine in rats. Eur Respir J 2002; 19: 1008-1014.

38 Eckel SP, Louis TA, Chaves PH, et al. Modification of the association between ambient air pollution and lung function by frailty status among older adults in the Cardiovascular Health Study. Am J Epidemiol 2012; 176: 214-223.

39 Chhabra SK. Acute bronchodilator response has limited value in differentiating bronchial asthma from COPD. J Asthma 2005; 42: 367-372.

40 Sherman CB. Late-onset asthma: making the diagnosis, choosing drug therapy. Geriatrics 1995; 50: 24-26. 